\title{
Food's other takeout
}

Written by: Robin Davis, OECD Observer

Last update: 3 March 2020

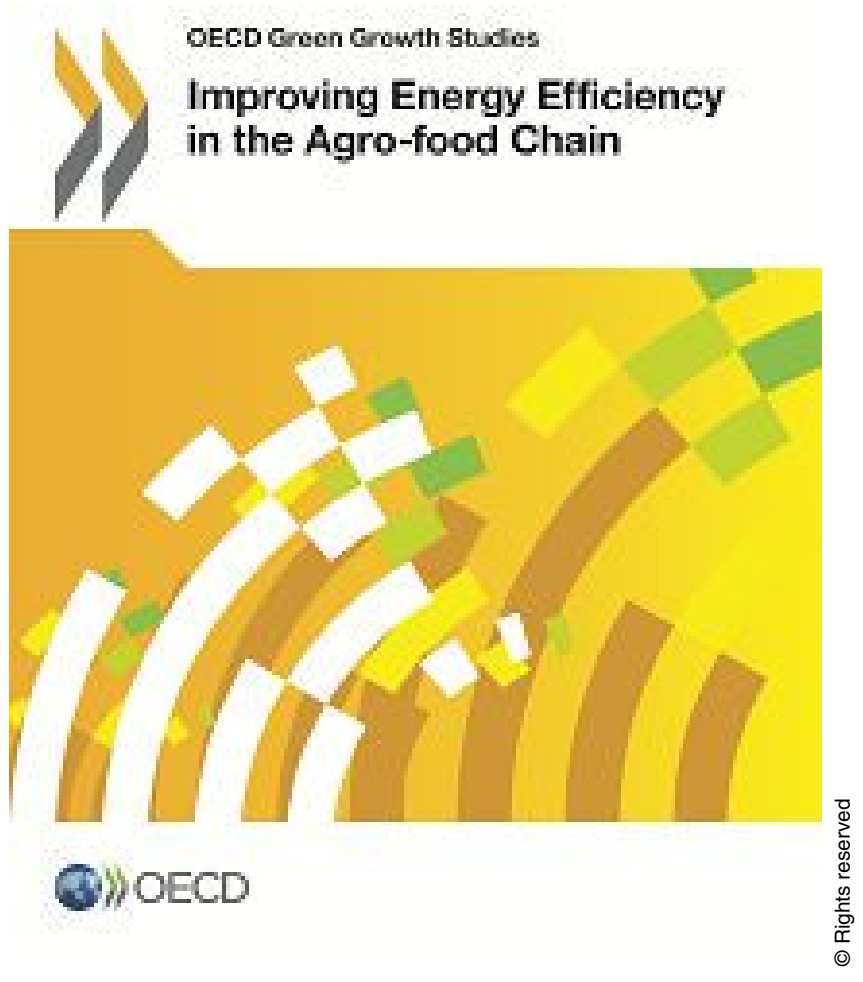

The popularity of the films Fast Food Nation, What the Health and Rotten has consumers everywhere concerned about the hygiene of their food, but what about the energy cost of producing it? Ready-to-eat food, whether fast food or a meal in a restaurant, may be convenient, but requires more energy to produce than less processed foods, such as fruits and vegetables, or conventional butcher meat. Your pre-washed packaged salads may make your life easier but at a cost for the environment.

Food production systems account for nearly $20 \%$ of energy usage in OECD countries, so clearly energy efficiency should become more important. Improving Energy Efficiency in the Agro-Food Chain sets out not only to help us understand energy efficiency in relation to our eating habits, but also how to improve it. Energy usage is expected to rise markedly in the coming decades due to technological advances, rising consumer incomes and changes in lifestyle that 
will contribute to different patterns of food consumption. Small household lifestyle changes such as eating out less and buying less processed food can boost energy efficiency. Reduction of food waste also helps: the Food and Agriculture Organization of the United Nations (FAO) estimated in 2011 that between a third and a half of food produced is wasted worldwide. Farming accounts for less than $30 \%$ of energy usage in the food chain, whereas waste makes up $38 \%$.

What about climate change? Extreme weather increases energy usage in farming, which is already a major emitter of greenhouse gases. Drought conditions require more energy to irrigate crops, while more fuel is needed to run machines and tractors in wet conditions.

There are many ways to improve energy efficiency, including raising public awareness, and improving know-how and technology. But as with so many challenges, best practices begin at home, including at the dinner table.

@OOECD Observer No 312 Q4 2017

\section{References}

OECD (2017), Improving Energy Efficiency in the Agro-food Chain, OECD Publishing, Paris. http://dx.doi.org/10.1787/9789264278530-en http:// dx.doi.org/10.1787/9789264278530 